\title{
Competitive advantage of the sustainable digital economy
}

\author{
Oksana Nurova $^{1 *}$, Tatiana Freze ${ }^{1}$ \\ ${ }^{1}$ Institute of Engineering and Environmental Security, Togliatti State University, Belorusskaya str. 14, \\ 445020 Togliatti, Russian Federation
}

\begin{abstract}
This research focuses on factors that influence the competitive advantage of the sustainable digital economy. Digital economy helped to speed up the exchange of information flows which, in turn, impacted on the creation the new forms of business and socio-economic interactions. Such sectors as banking and finance or hospitality and services are all influenced by the advancements of the digital economy that include sharing economy or Blockchain technology and its related applications. In this article, we show that digital economy is more sustainable due to the fact that it requires less energy sources and can itself contribute to the formation of the green economy and the acceptance of the renewable energy. All these features constitute its competitive advantage that needs to be further supported and fostered. In addition, we discuss key strategies and the development of skills to adapt to a digital economy and provide an overview of high-quality training for high-tech workers. It was assumed that in future, people would be able to easily acquire new skills through vocational training and vocational training. However, the spread of digital technologies has changed the way we work and has increased the need for high-quality training for workers in a wide range of professions. To use such technologies effectively, workers in an increasing number of sectors and professions need both general and advanced ICT skills.
\end{abstract}

\section{Introduction}

The main feature of the digital economy is that geographical location is no longer a competitive advantage and that the main role is played by the use of digital technologies such as cloud computing, mobile devices and smart contracts [1]. The digitalisation of the economy is considered a key factor in developing sustainable competitive advantages for the economy in general [2]. Traditional industrial structures and business models are being destroyed, and the boundaries between business and technology functions are blurring. Technology has become a catalyst for corporate strategy and transformation, expectations of IT have shifted, prompting many organizations to rethink the role of technology and rethink traditional operating models and organizational structures [3].

In general, there is a new approach to help business and technology functions collaborate more effectively, innovate and create new sources of value. Technology has become a crucial

\footnotetext{
* Corresponding author: oksana.nurova@gmail.com
} 
part of the global economy and a sustainable competitive advantage that is growing exponentially. The merging of the physical and digital worlds confuses the value chain, blurs the boundaries of the industry, and disrupts traditional value-added models. We expect that more than 90 percent of global production, retail, finance, healthcare, energy, and transportation will be connected to Industry 4.0, where digital platforms will be coupled and connected to their physical counterparts [4]. Therefore, the digital economy presents a challenge to these companies in terms of compliance requirements.

Digital innovation also brings new challenges in dealing with the integration of the physical and digital worlds, as well as a number of new supply chain challenges. It is our duty to force these companies to adapt their organisational and production patterns in order to remain competitive [5]. What is new is the exploration of a selective approach that focuses on start-ups with better potential, creating a specific business environment consistent with their ability to promote and sustain their growth. Another challenge is that we want to define a development path for developing a sustainable competitive advantage in the digital economy and a sustainable competitive advantage. There is the need to align entrepreneurship with regional economic development. Moreover, there is a dynamic importance of an ecosystem useful for scale development and for business development and highlights the benefits that this ecosystem offers. In addition to the challenges associated with digital technology, there are also a number of challenges associated with digital technologies, such as access to capital, the use of technology and developing a competitive advantage in the digital economy. For example, insurance companies use digital networks to stay ahead of development, and collaboration is critical for companies to harness the power of the Internet of Things (IoT). Today's technology start-ups compete for digital innovation by developing solutions that leverage and create synergies in industries such as home automation and healthcare. Innovators enable reusable solutions to be created that allow local teams to design their products and services and gain a competitive advantage [6].

In the environmental field, our aim is to become a global role model in the digital economy. For example, the European Union has become a pioneer and needs to review its objectives in this area. The broader strategy for the future of Europe includes a strategy for the digital economy. This is not only the goal for Europe, but for all EU member states and the European Union [7].

As the digital economy continues to evolve, it may seem more difficult than ever to maintain our market leadership. Even if one keeps pace with the pace of innovation in other sectors of the economy, such as technology, this can cause serious problems. Add to that the fact that technologies are converging exponentially, and countless technologies are changing business models overnight, and it may seem that a sustainable advantage is impossible. Today, the only way for most companies to maintain their competitive advantages is to adapt to continuous digital transformation, to meet new pressures, keep pace with competition and take advantage of new technologies. By bringing advantages to already more developed economies, first-movers can assume a dominant position in national economies that will be difficult for latecomers to challenge. Thence, the question is how the majority of developing countries can maximize the potential opportunities of the digital economy. Global competitors will not have an easy time outdoing themselves, so developing countries should be able to create sizeable niches that allow rapid growth, as Singapore and South Korea have done. This means looking at building local strengths, recognising what local businesses can do and taking advantage of the specific local circumstances. For example, some countries set up a regulatory laboratory to anticipate and develop future legislation on the use and application of new technologies. Business hubs to promote healthy competition in the telecommunications sector and a regulatory environment conducive to the diffusion of new technology. To achieve these goals, policymakers could introduce testing and learning 
approaches to developing new technologies and their solutions [8]. Through testing and learning, they can encourage companies to innovate and test new digital products.

\section{Technology platforms and digital sustainable economy}

Globalisation and the digital economy have brought unprecedented growth to all segments of the public and private sectors and opened up a globally accessible market. The world has become a marketplace for companies of all sizes to provide cross-border services to a global customer base, and geographical reach is growing [9]. All of these provide a reflection on the role of technology in the future. One needs to stress the need for governments and the private sector to work together to create a new digital ecosystem. Some countries such as China or India are well on its way to becoming a digitally advanced [10].

Similarly, emerging technologies such as cloud computing are reducing the cost of data and turning fixed-asset investment into operating costs into a pay-as-consumer model. A connected nation is transforming into a digital economy with a more efficient and efficient public and private sector. Driven by falling costs and increasing data availability, India is digitalizing faster than many developed economies and emerging economies, and is already on the fastest-growing base in the world in terms of the number of mobile phones, tablets, and smartphones. Indians spend more time on social media, download more than twice as much data as their counterparts in other countries, and now account for a share of GDP compared to the last decade. More than half of all mobile phone purchases in India $(52.5 \%)$ are now made on mobile devices, up from $45 \%$ in 2010. The Global E-Commerce Framework sets out five principles that guide the development of the digital economy and its continued high growth potential $[11,12]$.

New technologies reduce costs, enable market share and offer new products and services that were not previously needed. Technology platforms include, but are not limited to, cloud computing, mobile devices, social media, e-commerce platforms and mobile applications. This, combined with the development of new business models and the use of technology in the digital economy, contributes to the development of new activities in both the private and public sectors. New technologies offer lower barriers to entry, lower operating costs and lower prices, thereby reducing costs. The digital economy, individually and collectively, is using technology to overhaul traditional exchanges and enable new ones. Many entrepreneurs have taken advantage of technology - and driven digital economies to create new businesses and new business models that would not have existed without the size and scale they have today or in previous generations [13].

There are various concepts for business platforms that can help to structure the technological framework that allows the digital platforms to go live. This can bring the business and technology solution back to completion and make it available to the customers and partners in a variety of business models. The customers should identify the business opportunities that arise from the introduction of innovative digital solutions. Digital transformation transactions with the customers are managed in a variety of business models, from small businesses to large corporations and large corporations [14].

All in all, it becomes clear that leading digital platforms have an impact on individuals, markets and society. It has redefined the world economy by creating a new economic space and changing the way analogous activities are conducted. It has had a significant economic impact on people and businesses, and the first is to refocus organizations to make them more responsive to the needs of their customers and customers. Secondly, we need to use digital technology to change the nature of businesses and the way the economy is changing. We can think of it as a digital transformation or a digital transformation in two parts. One is its use and its destination, the other is actually changing the way we make this journey. However, considering the potential that one sees in science fiction films, where everything is connected 
with a snap of a finger and everything happens in a flash, it will take more than digital infrastructure and technology to realize this potential of the digital economy.

\section{Stages of development of the sustainable digital economy}

Today, sustainable digital technology accounts for a share of GDP compared to the last decade and represent a significant part of the overall growth of the global economy in recent years. New technologies reduce costs, provide market access, offer new products and services that were not needed before, and provide access to new markets and new opportunities for new businesses [15]. Together with the rapid growth of the digital economy and the development of new business models, this has contributed to the development of new activities in both the private and public sectors. The Global E-Commerce Framework sets out five principles that guide the implementation and development of digital economies in order to maintain their high growth potential [16].

The artificial intelligence (AI) is considered a production factor based on its self-acquired skills, which have developed noticeably over time, and its use in machine-based technologies. The potential benefits could be even greater if governments invest more in innovative technological advances and the adoption of artificial intelligence that enhances the business sector. AI is seen as adding new productivity factors to existing factors. Therefore, the question is how the majority of developing countries can maximize the potential opportunities of the digital economy [17].

Some developing countries should be able to create sizeable niches that allow rapid growth, as Singapore and South Korea have done. By bringing advantages to already more developed economies, first-movers can establish a dominant position in national economies that are difficult for laggards to challenge [18]. This means building on local strengths, recognising what local companies can do to make it less likely for global competitors to compete with them, and taking advantage of the specific local circumstances.

The role of digital transformation is developing with the accelerated introduction of the third platform [19]. More technologies are added to the third platform and more opportunities to experience the additional layers of innovation, innovation and innovation in the digital economy. Through cost optimization, innovation, and the creation of competitive differentiation, digital transformations are becoming the cornerstone of progress. But we must not be under any illusions that, despite these technologies, there is still a human dimension, which is strengthened by the process of information and the development of the third platform. Digital transformation efforts and strategies are often the result of a combination of government, private, and civil-society initiatives. In countries like Japan, digital change is even aimed at influencing all aspects of life through the Society 5 initiative, which focuses on education, health, employment, education, and social mobility [20]. It is a question of harnessing the power of technology to accelerate the impact on society in such a way that priority is given to social and economic development and the development of the third platform. The information-driven ecosystem of the digital economy in the United States and other countries is the result of a combination of government, private, and civil-society initiatives, led by the United States Department of Commerce, the Federal Reserve Bank of New York, and the National Institutes of Health. Stagnant countries, such as Australia and the United States, have strong growth histories, but are slowing down and at risk of falling behind. Some countries including New Zealand and the UK have shown high levels of digital development, continuing to lead in innovation and new growth. Stagnant countries (including Australia and the United States) have low growth rates and high innovation rates, but have strong growth histories [21]. The first call for project proposals focuses on forward-looking areas, with a focus on the development of new technologies and new business models. The strategy prioritises innovation and innovation - centred projects in areas such as data analysis, 
data science and data management. It focuses on new technologies, innovation, technological development, the development of the digital economy and technological innovation.

\section{Science and education in the digital economy}

The role of teachers is changing in the digital economy and the changing value orientation of consumers in society is creating a new type of student within the education system. The education of the future is currently going through a timeframe for educational institutions that are taking advantage of the unique opportunities of networks and digital technologies to involve both direct and indirect actors in education processes [22]. This is the so-called "network interaction" of students, teachers, parents and other educational actors. This allows the traditional framework of education to be extended to ensure continuous improvement of educational pathways. At the same time, the psychological and educational characteristics of the modern generation should be taken into account when designing a digital educational environment [23].

The modern transformation of our education system shows that reforms aimed at training future staff lead to people who need to develop and retrain in accordance with the demands of the labour market. The global education market is an important contribution to the growth of the global labour market and to the global economic growth of the future. In these circumstances, the improved education model has become the basis for the development of the global labour market and the growth of the digital economy. The construction of the technology centres in some cities leads to the development of a high-quality research and development environment for the future of technology. Much work is being done to train highly qualified engineers and future scientists and to further improve the quality of the research and development environment for the future of technology in the country. Scientific knowledge describes the world through technology and the transformation of the modern world. It plays a crucial role in the development of new technologies such as artificial intelligence, robotics and machine learning, among many others.

A post-industrial society needs an economy based on knowledge, new technologies and human capital. There is a huge gap between what is required for a person and what it required of everyone. This has come to the fore in recent years with the rise of the Internet of Things and the development of smart cities. This era as we know it is about to change fundamentally the nature of human capital and the role of education in our society [24].

In dozens of countries in Asia, Europe and America the development of human capital and education as the basis for the digital economy are given particular importance. These activities aim to build human potential consistently through a combination of science, technology, engineering and mathematics (STEM) education and the use of technology. Large companies are trying to create public-private partnerships in higher education [25]. By strengthening integrated management and research projects to address the key problems facing the economic sector, we will further strengthen the role of science and education as a basis for the development of human capital and the digital economy. The large educational complex is based on joint action between universities and industry, with a focus on research and development and the development of new technologies and services. There are services based on big data processing technologies that use AI methods such as artificial intelligence, machine learning and big data analysis. In some sectors, such technologies face critical regulatory obstacles, which is why global development institutions that promote the global digitization agenda have developed a set of regulatory frameworks for the use of big data in developing countries. These are the legal obstacles to working with citizens' personal data. 


\section{Conclusions}

Overall, digital innovations are clearly changing the demand for skills, creating a huge skills gap that can hold back economic growth. Apprenticeships have the capacity to close this skills gap by equipping people with the skills they need to adapt to the emerging digital economy and equipping them with skills for jobs that may become obsolete during the transition. Although the emergence of digital economies is creating new jobs all the time, many of these jobs could become obsolete in the future. Training courses should not be limited to traditional craft professions, as their scope to provide an effective and efficient training model is also increasingly recognised in the technological sector. There are good jobs that do not require a bachelor's degree to secure them and they can lead to the development of high-quality apprenticeships for these growing sectors of the digital economy by providing access to high-quality training in digital skills such as web development, data analysis and machine learning. The improvement of labour systems can be supported through improved access, better labour market analysis and the promotion of cooperation between industry and employers. Digital degrees and apprenticeships will be designed by leading employers in the digital sector. One should aim at creating high quality training programmes that meet the standards defined by the employer with a purpose to produce top-notch graduates in the fields of technology, including computer science, computer engineering, information technology, data science and data analysis.

Today, many employers coordinate work-based learning and work closely with learning platforms such as Google, Microsoft, IBM and others. Employers coordinate work-based learning and work closely with their digital partners and governments through the learning platforms. The strength of this approach is that it gives employers a clear understanding of the skills they need to build their business. Organizations must define precisely the skills that help workers move forward and show them the new career paths that can result from employees' time and effort. As technology and influence continue to transform today's labour market, developing new basic skills has become imperative, both at the personal and corporate levels.

At the same time, the new technology has demonstrated the ability to perform tasks that workers did not perform as well as they did in the past. While this trend continues, workers need to upgrade their existing skills and acquire new skills throughout their careers. This new environment requires an overhaul of the outdated model of education in which people could expect to acquire education and skills at a young age that will last their entire careers. Employers must also be given additional tools to acquire new skills and learning opportunities during their careers. Furthermore, employers play a unique and critical role in training workers, but most education efforts are not relevant to current and future needs. Moreover, employers, individuals, and universities must work together to modernize their education programs and find timely programs that are relevant and worthwhile. Although many, if not all, industries have already been destroyed, the good news is that researchers expect these jobs to increase overall employment opportunities. Infosys and the Milken Institute conducted a survey to find out what employees want from training programs and what employers need to stay competitive. At-the-job training is limited as an option for prospective workers. For workers already in higher-skilled positions, vocational training is more than twice as common, making those in more automated positions even more vulnerable to displacement. Digital technologies are key to reducing this gap, as tools can increase the reach and accessibility of training and skills tools and are at the top of the demand. Many of today's workers have not been trained since the 1970s, when the ubiquitous technologies of today did not exist. Nowadays, digital skills are the top priority to succeed in today's workplace for most of the young employees. Any college degree is good enough to give 
virtually anyone the best career path. As the global economy continues to undergo sustainable digital transformation, high-tech skills will become a passport to job and personnel security.

\section{References}

1. T.J. Sturgeon, Global Strategy Journal, 11(1), 34-57 (2021)

2. S. Bag, G. Yadav, P. Dhamija, K.K. Kataria, Journal of Cleaner Production, 281, 125233 (2021)

3. J. J. Yun, X. Zhao, J. Wu, J.C. Yi, K. Park, W. Jung, Sustainability, 12(5), 1883 (2020)

4. S. Shan, Y. Luo, Y. Zhou, Y. Wei, Technology Analysis \& Strategic Management, 31(4), 406-420 (2019)

5. H. Viswanathan, P.E. Mogensen, IEEE Access, 8, 57063-57074 (2020)

6. H. Legenvre, M. Henke, H. Ruile, Journal of Purchasing and Supply Management, 26(1), $100596(2020)$

7. D.J. Teece, Research Policy, 47(8), 1367-1387 (2018)

8. W. Strielkowski, T. Veinbender, M. Tvaronavičienè, N. Lace, Economic ResearchEkonomska Istraživanja, 33(1), 788-803 (2020)

9. S. Dhir, R. Rajan, V. Ongsakul, R.A. Owusu, Z.U. Ahmed, Thunderbird International Business Review, 63(1), 43-61 (2021)

10. A.K. Awasthi, J. Li, Renewable and Sustainable Energy Reviews, 76, 434-447 (2017)

11. M. Fromhold-Eisebith, G. Eisebith, World Development, 123, 104614 (2019)

12. A. Borthakur, M. Govind, Journal of Environmental Planning and Management, 62(4), 717-740 (2019)

13. N. Abbas, Y. Zhang, A. Taherkordi, T. Skeie, Internet of Things Journal, 5(1), 450-465 (2017)

14. M. Kotarba, Foundations of Management, 10(1), 123-142 (2018)

15. D. Trabucchi, T. Buganza, E. Pellizzoni, Research-Technology Management, 60(2), 4352 (2017)

16. D. Tolstoy, E.R. Nordman, S.M. Hånell, N. Özbek, Journal of World Business, 101165 (2020)

17. M. Zhang, M. Chen, China's digital economy: Opportunities and risks (2019)

18. D.N.Y. Mah, D.M.W. Cheung, Sustainability, 12(12), 4818 (2020).

19. K.S. Warner, M. Wäger, Long Range Planning, 52(3), 326-349 (2019)

20. A.V. Mavrodieva, R. Shaw, Sustainability, 12(5), 1893 (2020)

21. K. Rijswijk, L. Klerkx, J.A. Turner, NJAS-Wageningen Journal of Life Sciences, 90, 100313 (2019)

22. N.N. Pokrovskaia, M.Y. Ababkova, D.A. Fedorov, Education Sciences, 9(3), 183 (2019)

23. V. März, G. Kelchtermans, K. Vermeir, Journal of Educational Change, 18(4), 439-464 (2017)

24. C. Zheng, J. Yuan, L. Zhu, Y. Zhang, Q. Shao, Journal of Cleaner Production, 258, $120689(2020)$

25. C.S. Chai, The Asia-Pacific Education Researcher, 28(1), 5-13 (2019) 